\title{
Hybrid Coronary Revascularization: Perspective Current State After 25 Years of Start
}

\author{
Ahmed Abdelrahman Elassal, MD, ${ }^{1,2}$ Khalid Ebrahim Al-Ebrahim, FRCSC, ${ }^{1}$ Adel Mohammad Makhdoom, MD, ${ }^{3}$ \\ Mazin Adel Fatani, FRCSC, ${ }^{4}$ Mohamed Hasan Ibrahim, MD, ${ }^{5}$ \\ ${ }^{1}$ King Abdulaziz University, Department of Surgery, Cardiac Surgery Unit, Jeddah, Saudi Arabia; ${ }^{2}$ Zagazig University, Cardiothoracic \\ Surgery Department, Zagazig, Egypt; ${ }^{3}$ King Abdulaziz University, Department of Anesthesia and Critical Care, Jeddah, Saudi Arabia; \\ ${ }^{4}$ Umm Al-Qura University, Department of Surgery, Makkah, Saudi Arabia; ${ }^{5}$ Benha University, Department of Cardiology, Benha, Egypt
}

\section{ABSTRACT}

Hybrid coronary revascularization (HCR) represents a minimally invasive revascularization strategy in which the durability of the internal mammary artery to the left anterior descending artery graft is combined with percutaneous coronary intervention to treat remaining lesions. It first was introduced in the mid-1990s and aspired to bring together the "best of both worlds" - the excellent patency rates and survival benefits associated with the durable left internal mammary artery graft to the left anterior descending artery alongside the good patency rates of drug-eluting stents, which outlive saphenous vein grafts to non-left anterior descending vessels. Although in theory this is a very attractive revascularization strategy, several years later, only small randomized controlled trials comparing HCR with coronary artery bypass grafting has recently emerged in the medical literature, raising concerns regarding HCR's role. In the current review, we discuss HCR's rationale, the current evidence behind it, its limitations, and procedural challenges.

\section{INTRODUCTION}

Optimal revascularization strategy in multivessel coronary artery disease (MV-CAD) remains unresolved [Ganyukov 2020]. Coronary artery bypass grafting (CABG) using the left internal mammary artery (LIMA) has excellent longterm patency with improved survival. However, saphenous vein grafts (SVG) have significantly worse long-term patency [Harskamp 2015].

Advances in stent technology have resulted in reduced rates of thrombosis and restenosis, making PCI a viable alternative to coronary surgery in selected patients. While multivessel PCI with newer-generation drug-eluting stents (DES) is an attractive strategy, use of the LIMA to the left anterior

Received February 2, 2021; accepted March 3, 2021.

Correspondence: Abmed Abdelrahman Elassal, King Abdulaziz University, feddah, Saudi Arabia, 21589; $00966126408222-00966566490807$ (e-mail: samalassal1434@gmail.com). descending artery (LAD) provides the most predictable longterm results [Taggart 2016]. Hybrid coronary revascularization was first described by Angelini et al in 1996 [Angelini 1996]. He used the classic minimally invasive direct coronary artery bypass procedure, in which the LIMA is harvested by direct vision through a fourth interspace left mini-thoracotomy, and the LIMA is sutured to the LAD on the beating heart. The advantage of this form of revascularization was already validated with a few studies in the era of BMS [de Cannière 2001] and after diffusion of DES [Murphy 2004].

HCR was introduced as a pioneering treatment approach to multivessel coronary artery disease (CAD), hoping to bring together the "best of both worlds" [Lioyd 1999]. HCR aims to reduce surgical trauma while preserving long-term survival and minimizing adverse cardiovascular events [Vasileios 2015]. Dr Halkos and colleagues have provided a preponderance of evidence over a wide variety of settings that hybrid coronary revascularization (HCR) is safe, feasible, and potentially advantageous in selected populations when compared with conventional coronary artery bypass [Halkos 2014]. Thus, is HCR the future in coronary revascularization? The results from the practice patterns in the United States described by Harskamp et al warrant caution [Harskamp 2014]. The learning curve, financial and time commitment, and need for a hybrid operating room create stringent requirements that many programs will not be able to support. In addition, the clinical benefit of HCR over CABG has not been evaluated by a large, randomized trial [Igor 2014].

What is hybrid coronary revascularization (HCR)? Hybrid coronary revascularization (HCR) is defined as a planned combination of surgical coronary artery bypass and percutaneous coronary intervention (PCI) to treat multivessel coronary artery disease $(\mathrm{CAD})$. It is performed either during the same procedure or in a staged approach within 60 days, regardless of the sequence of procedures or its location [Harskamp 2015]. However, many authors include the terminology of minimally invasive surgery into the definition of HCR. Hybrid coronary revascularization most commonly combines a minimally invasive $\mathrm{CABG}$ procedure involving a left internal mammary artery (LIMA)-to-left anterior descending artery (LAD) bypass with PCI using drug eluting stent (DES) or bare-metal stent (BMS) to non-LAD vessels, 


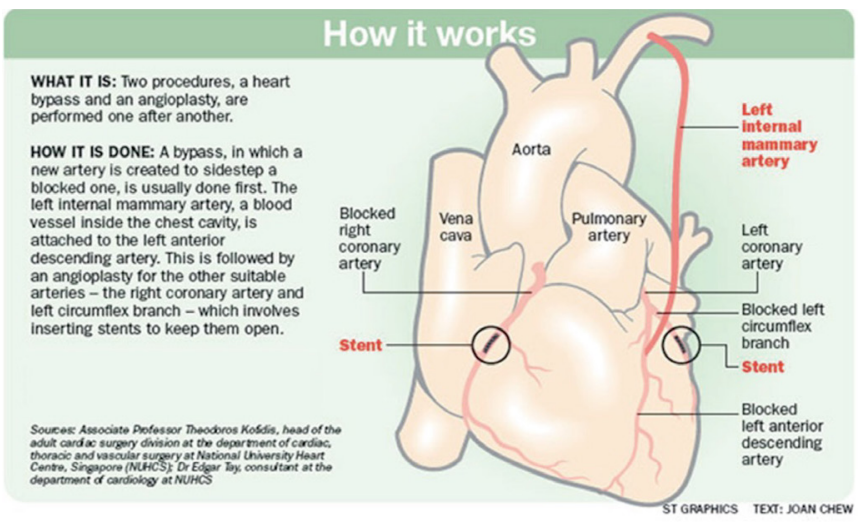

Figure 1. The concept of hybrid coronary revascularization [Giambruno 2017].

which is the most proven efficacious therapeutic proposal of cardiac surgery and interventional cardiology and also increasingly has been used to treat multivessel coronary artery disease [Giambruno 2017]. Hybrid coronary revascularization was intended to incorporate the principal benefits of both procedures, specifically decreasing the risk of surgery by using a limited left thoracotomy approach for durable anterior wall revascularization, with a left internal mammary artery graft, while treating disease in other coronary territories with PCI. HCR aims to reduce recovery duration, hospital complications, and surgery trauma [Harskamp 2014] (Figure 1).

\section{Indications and patient selection}

The ideal candidate for HCR has multivessel CAD involving the $\mathrm{LAD}$ and/or left main coronary arteries with at least one other coronary artery stenosis amenable to PCI [Rastan 2009] (Table 1). An important anatomical feature favoring HCR should be plaque burden in the proximal LAD well characterized by the SYNTAX (SYNergy Between PCI With TAXUS and Cardiac Surgery) score [Sianos 2005]. The classic indication for HCR is multivessel CAD including: 1) a proximal complex LAD lesion with optimal distal anatomy amenable to LIMA-to-LAD grafting; 2) non-LAD lesions amenable to PCI, in a patient with no contraindications to dual antiplatelet therapy (DAPT); and 3) a high likelihood of achieving "reasonable complete revascularization" with such an approach. Complex distal left main lesions also are ideal for HCR if the circumflex artery territory is amenable for PCI [Rastan 2009; Bonatti 2010]. HCR appears particularly appealing for patients with the aforementioned coronary anatomy and others considered too high risk for open cardiopulmonary bypass surgery via midline sternotomy, including those with a high risk of deep sternal wound infection (e.g., diabetics, morbidly obese), severely impaired left ventricular function, chronic kidney disease, significant carotid or neurological disease, severe aortic calcification, prior sternotomy, and lack of venous conduits [Bonatti 2010]. The 2011 American College of Cardiology Foundation/American Heart Association guidelines for CABG state that the "primary purpose of performing HCR is to decrease the morbidity rate of traditional CABG in high-risk patients"
Table 1. Candidates for HCR Versus Conventional CABG [Giambruno 2017].

\begin{tabular}{lccc}
\hline Characteristic & PCl & HCR & CABG \\
\hline Angiographic characteristics & & & \\
ULMD & - & + & + \\
Intramyocardial LAD & + & - & - \\
Complex LAD lesion & - & - & + \\
Complex non-LAD lesion & - & - & + \\
Comorbidities & & & \\
Advance age & + & + & - \\
Frailty & + & + & - \\
LVEF <30\% & - & + & + \\
Diabetes mellitus & - & + & + \\
Renal insufficiency & - & + & + \\
Severe chronic lung disease & + & - & - \\
Prior left thoracotomy & + & - & + \\
Prior sternotomy & + & + & - \\
Limited vascular access & + & + & - \\
Lack of available conduits & + & + & - \\
Severe aortic calcification & + & + & - \\
Contraindication for DAPT & - & + \\
\hline & & & \\
\hline
\end{tabular}

+ = recommended; - = not recommended

CABG, coronary artery bypass graft; DAPT, dual antiplatelet therapy; HCR, hybrid coronary revascularization; LAD, left anterior descending artery; $\mathrm{LVEF}$, left ventricular ejection fraction; $\mathrm{PCl}$, percutaneous coronary intervention; ULMD, unprotected left main disease

[Hillis 2011]. It states that HCR (defined as the planned combination of LITA-to-LAD artery grafting and PCI of $\geq 1$ non-LAD coronary arteries) is reasonable in patients with one or more of the following (level of evidence: B): Limitations to traditional CABG, such as heavily calcified proximal aorta or poor target vessels for CABG (but amenable to PCI); lack of suitable graft conduits; unsuitable LAD artery for PCI (i.e., excessive vessel tortuosity or chronic total occlusion) Class IIa. However, it may be reasonable as an alternative to multivessel PCI or CABG in an attempt to improve the overall risk-benefit ratio of the procedures (level of evidence: C) Class IIb [Hillis 2011]. Even in the more recent European Society of Cardiology/European Association for Cardio-Thoracic Surgery guidelines on myocardial revascularization, HCR has a Class IIIb recommendation for specific patient subsets and only at experienced centers [Neumann 2018].

In the Canadian Cardiovascular Society/Canadian Association of Interventional Cardiology/Canadian Society of Cardiac Surgery Position Statement on RevascularizationMulti-vessel Coronary Artery Disease is stated that HCR [Teo 2014]: 


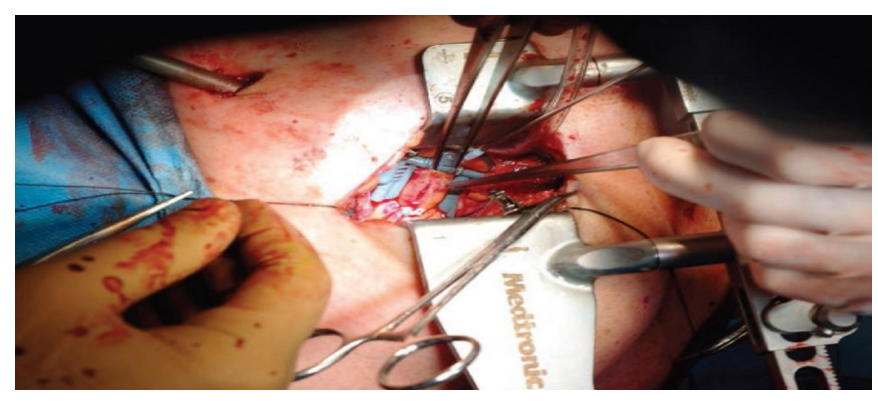

Figure 2. Distal anastomosis through the left small thoracotomy (MIDCAB) [Bachinsky 2012].

1. Is typically performed with minimally invasive incisions.

2. Combines the advantage of the LITA-to-LAD graft with the less invasive nature of PCI.

3. Studies to date have demonstrated HCR to be safe and effective, but definitive data (e.g., randomized trials) are lacking.

The lack of several large randomized controlled trials (RCTs) involving different risk groups, hinders the identification of an HCR target group [Windecker 2014]. Consequently, physicians and surgeons do not embrace HCR in routine clinical practice. In a study from the Society of Thoracic Surgeons (STS) Adult Cardiac Surgery Database, HCR represented just $0.48 \%$ ( $\mathrm{N}=950$ patients) of the total CABG volume $(\mathrm{N}=198,622)$ between July 2011 and March 2013 [Harskamp 2014].

\section{Evolution HCR components, minimally invasive surgical bypass techniques}

One of the major disadvantages of a standard CABG is the median sternotomy incision, with the attendant discomfort and temporary limitations on activity as well as the risks of complications, including sternal instability and infection causing delayed recovery (Table 3). Patients undergoing a standard CABG also often require cardiopulmonary bypass, and manipulation of the aorta increases the risk of stroke and reduced cognitive function [Saha 2018].

Accordingly, surgical techniques have evolved with the goal of minimizing complications while attempting to achieve long-term patency of bypass grafts [Saha 2018].

Although HCR does not necessarily point to utilization of minimally invasive techniques for LIMA harvesting and grafting to LAD, it often is employed for these procedures. The benefits of minimally invasive techniques as compared with conventional surgical techniques is the avoidance of such complications [Saha 2018].

The most commonly used surgical techniques are minimally invasive direct coronary artery bypass (MIDCAB), endoscopic atraumatic coronary artery bypass (endoACAB), robotic-assisted endoACAB, and total endoscopic coronary artery bypass (TECAB).

Minimally invasive direct coronary artery bypass grafting (MIDCAB) is performed on the beating heart through a small, left-sided thoracotomy in the $4 \mathrm{th} / 5$ th interspace via

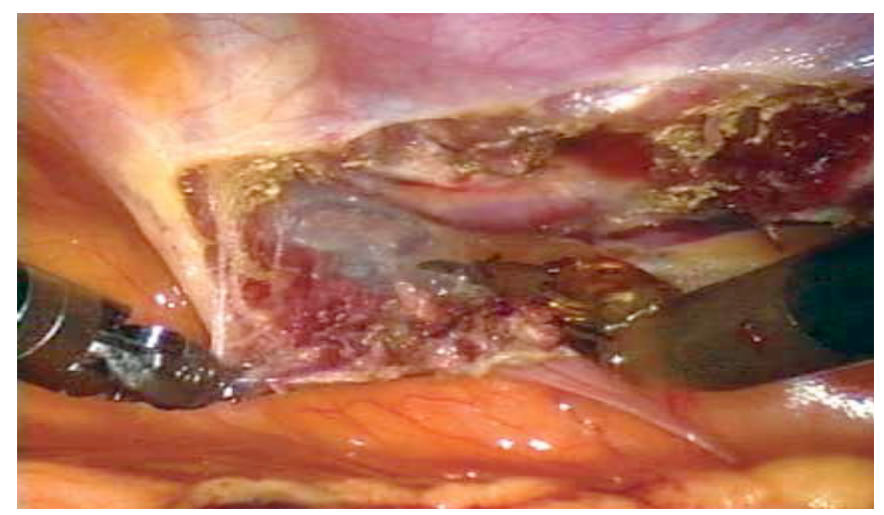

Figure 3. Thoracoscopic LIMA harvesting [Harskamp 2013].

direct visualization (Figure 2). To avoid the significant chest wall manipulation associated with MIDCAB and to improve postoperative pain control, thoracoscopic and robotic techniques have been developed. This includes the endoscopic atraumatic coronary artery bypass (endoACAB), which allows thoracoscopic/robotic LIMA identification and mobilization followed by a direct non-rib spreading thoracotomy permitting hand-sewn anastomosis on the beating heart [Vassiliades 2009] (Figure 3). It also includes the totally endoscopic coronary artery bypass grafting either on- or off-pump, in which the anastomosis is performed intracorporeally using a robot. The latter, although challenging, produces a reported clinical freedom from graft failure as high as $98.6 \%$ at 13 months in experienced hands [Srivastava 2010].

\section{Evolution of DES and percutaneous techniques}

First-generation DES (sirolimus and paclitaxel eluting) are associated with a 2\% 1-year and up to 5\% 10-year risk of stent thrombosis [Yamaji 2016]. The development of secondgeneration stents with thinner struts, more compatible polymers, and effective cytostatic drugs resulted in reductions in mortality (0.4 versus $3.1 \%)$ and major adverse cardiovascular and cerebral events (MACCE) in patients with multivessel disease [Nakayoshi 2016].

Although newer-generation DES have decreased risks of thrombosis and restenosis, the need for target vessel revascularization remains a concern for patients undergoing a hybrid procedure [Harskamp 2014].

Radial intervention is preferred to minimize vascular and bleeding complications. Also, all patients undergoing HCR should have the ability to tolerate dual antiplatelet therapy (DAPT) for at least three months and up to 12 months or longer, according to the clinical presentation and relative risks of ischemia versus bleeding [Moreno 2020].

The sequence and timing of HCR procedures - three possible timing strategies can be used: CABG and PCI performed simultaneously; CABG first followed by PCI; or CABG following PCI.

The question of where to perform HCR and the best sequence, concurrent versus staged, remains unresolved.

1. Concurrent (1 stage) approach: It is the most compelling approach in which during the same session, 
Table 2. Advantages and disadvantages of one stage and two stages HCR [lgor 2014]

\section{Central ILlustration Advantages and Disadvantages of Simultaneous and Staged HCR Procedures}

\begin{tabular}{|c|c|c|}
\hline ONE STAGE (SIMULTANEOUS) & TWO & AGE HCR \\
\hline MID-CAB followed by PCI within minutes & MID-CAB 1st, then PCI & PCl 1st, then MID-CAB \\
\hline $\begin{array}{l}\text { Advantages } \\
\text { - LIMA-LAD graft can be studied by the } \\
\text { interventional cardiologist before PCI } \\
\text { stent implantation } \\
\text { - PCI to high-risk non-LAD lesions can be } \\
\text { performed with a protected LAD area } \\
\text { - In cases of unsuccessful stent } \\
\text { implantation, conventional CABG } \\
\text { remains an option } \\
\text { - Cost effective, as it reduces hospital } \\
\text { length of stay (single-step complete } \\
\text { revascularization) } \\
\text { - Patient satisfaction: condenses } \\
\text { revascularization therapy in one } \\
\text { patient encounter }\end{array}$ & $\begin{array}{l}\text { Advantages } \\
\text { - Allows angiographic validation of } \\
\text { the LIMA-LAD graft } \\
\text { - Full antiplatelet inhibition following } \\
\text { CABG with no perioperative } \\
\text { bleeding risk } \\
\text { - Protected anterior wall, lowering } \\
\text { procedural risks during PCl of } \\
\text { non-LAD vessels } \\
\text { - On some occasions, after minimally } \\
\text { invasive LIMA to LAD, patients } \\
\text { become asymptomatic in the } \\
\text { immediate post-operative period }\end{array}$ & $\begin{array}{l}\text { Advantages } \\
\text { - Allows angiographic evaluation of the } \\
\text { size of LIMA } \\
\text { - Lower risk of ischemia during the } \\
\text { MID-CAB in a partially revascularized } \\
\text { heart } \\
\text { - Useful in the setting of acute } \\
\text { myocardial infarction when culprit is a } \\
\text { non-LAD lesion } \\
\text { - In cases of unsuccessful stent } \\
\text { implantation, suboptimal CABG can be } \\
\text { performed }\end{array}$ \\
\hline $\begin{array}{l}\text { Disadvantages } \\
\text { - Only feasible in hybrid suites, featuring } \\
\text { state-of-the-art surgical and } \\
\text { interventional equipment } \\
\text { - Inflammatory response to surgery } \\
\text { offers a risk for stent thrombosis } \\
\text { - Dual antiplatelet therapy increases } \\
\text { the risk of bleeding } \\
\text { - Chronic kidney disease patients are } \\
\text { exposed to the dual nephrotoxic insult } \\
\text { of surgery and contrast media } \\
\text { utilization }\end{array}$ & $\begin{array}{l}\text { Disadvantages } \\
\text { - Risk of ischemia of non-LAD } \\
\text { territories during the LIMA-LAD } \\
\text { grafting (although this is very } \\
\text { unlikely in stable patients) } \\
\text { - Risk of a high-risk surgical } \\
\text { reintervention in case of an } \\
\text { unsuccessful PCl }\end{array}$ & $\begin{array}{l}\text { Disadvantages } \\
\text { - No angiographic control of } \\
\text { LIMA-LAD graft } \\
\text { - Higher risk of stent thrombosis during } \\
\text { surgery (due to inflammatory response } \\
\text { to surgery/discontinuation of dual } \\
\text { antiplatelet therapy/platelet transfusion) } \\
\text { - Increased perioperative bleeding } \\
\text { risk due to dual antiplatelet therapy } \\
\text { during surgery } \\
\text { - Risk of adverse events in the LAD } \\
\text { territory during the between- } \\
\text { stages interval }\end{array}$ \\
\hline
\end{tabular}

Panoulas, V.F. et al. J Am Coll Cardiol. 2015; 65(1):85-97.

CABG = coronary artery bypass grafting; $\mathrm{HCR}=$ hybrid coronary revascularization; $L A D=$ left anterior descending artery; LIMA $=$ left internaL mammary artery; $\mathrm{MI}=$ myocardial infarction; $\mathrm{MID}-\mathrm{CAB}=$ minimally invasive direct coronary artery bypass grafting; $\mathrm{PCl}=$ percutaneous coronary intervention.

PCI and CABG are performed in a specially constructed hybrid suite. The proposed advantages of this approach include a shorter recovery time, shorter length of stay, and improved patient satisfaction. This procedure also allows complications to be resolved immediately and avoids the need for two separate procedures. Real-time angiography may be performed after the completion of LIMA anastomosis to assure the quality of the anastomosis and permit revision if needed and the possibility of direct conversion to CABG when PCI fails for a non-LAD lesion [Choi 2017]. Conversely, 1- stage HCR presents the possible disadvantages of a higher risk of bleeding, due to the use of dual antiplatelet therapy and a risk of stent thrombosis due to the inflammatory response to surgery, and its application is limited to large collaborating spaces, referred to as hybrid operating rooms [Choi 2017]. 
Table 3. Techniques Used for LAD Revascularization During HCR [Tajstra 2018]

\begin{tabular}{|c|c|}
\hline Abbreviation & Description of Surgical Procedure \\
\hline MIDCAB & $\begin{array}{l}\text { Minimally invasive direct coronary artery bypass grafting. Thoracic access: left-sided thoracotomy or lower partial mini-sternotomy. LIMA } \\
\text { harvest: direct vision. Anastomosis: direct vision. Single lung ventilation: improves exposure, not required. CPB: not required, but can be } \\
\text { performed by cannulation of femoral vein and artery (avoids aorta cross clamping and arresting the heart. }\end{array}$ \\
\hline Endo-ACAB & $\begin{array}{l}\text { Endoscopic atraumatic coronary artery bypass graft surgery. Thoracic access: non/limited rib-spreading left-sided thoracotomy. LIMA harvest: } \\
\text { robotic or thoracoscopically. } \\
\text { Anastomosis: hand-sutured. Single lung ventilation: required when robot is used. CPB: not required. }\end{array}$ \\
\hline TECAB & $\begin{array}{l}\text { Totally endoscopic coronary artery bypass graft surgery. Thoracic access: }- \text {. } \\
\text { LIMA harvest: -. Anastomosis: thoracoscopically (or robotic } \rightarrow \text { robotic-assisted CAB). Single lung ventilation: required. CPB: not required. }\end{array}$ \\
\hline OPCAB & $\begin{array}{l}\text { Off-pump CABG. Thoracic access: midline sternotomy. LIMA harvest: direct vision. Anastomosis: direct vision with stabilizers. Single lung } \\
\text { ventilation: improves exposure. }\end{array}$ \\
\hline CPB: no. & $\begin{array}{c}\mathrm{CAB} \text {, coronary artery bypass; } \mathrm{CABG} \text {, coronary artery bypass graft; } \mathrm{CPB} \text {, cardiopulmonary bypass; Endo-ACAB, endoscopicatrumatic } \\
\text { coronary artery bypass; LIMA, left internal mammary artery; MIDCAB, minimally invasive direct coronary artery bypass; OPCAB, off pump } \\
\text { coronary artery bypass; TECAB, totally endoscopic coronary artery bypass }\end{array}$ \\
\hline
\end{tabular}

2. A staged (2 stage) approach: include CABG first follow by PCI or vice versa. This is the most common approach, representing 85 percent of all HCR procedures. It requires a surgical bypass operation in a conventional operating room and percutaneous intervention in a pre-existing catheterization laboratory [Harskamp 2014].

In the staged approach, the optimal sequence (PCI first and then CABG versus CABG first and then PCI) depends on the coronary anatomy of the patient and the patient's clinical presentation. On one end of the spectrum, there is the risk of performing multivessel stenting in an unprotected LAD territory versus the need for reintervention in the presence of anastomotic problems [Igor 2014]. There were no significant differences in postoperative and medium-term outcomes between the CABG-first and PCI-first groups. Based on these results, it can be inferred that it is safe to opt for either CABG or PCI as the primary procedure in 2-stage HCR [Choi 2017]. CABG first is more common, followed by PCI the next day, weeks, or sometimes 1 to 2 months afterward [Lowenstern 2019]. It should be recognized, however, that peri-anastomotic edema may lead to the appearance of a pseudo-stenosis at the distal anastomotic sites for days or weeks post-procedure [Chen 2010]. Thus, PCI of the distal LIMA-LAD anastomosis generally should be avoided unless there is TIMI (Thrombolysis In Myocardial Infarction) flow grade 0 to 2 or ongoing ischemia, regardless of the severity of the stenosis. If PCI is required, it should be performed with an undersized, low-pressure balloon, with the goal of restoring patency only [Moreno 2020].

Technical considerations, hybrid operation room $(\mathrm{OR})$ for HCR:

1. Considerations for adapting: The fields of interventional cardiology and cardiovascular surgery are converging and moving more toward minimally invasive procedures. Hybrid ORs are becoming a standard part of cardiovascular programs and offer the potential to transform how an institute's cardiac care is managed and delivered. HCR in a hybrid OR combines different modalities of treatment into a team approach. There are benefits to building this approach, and they're entirely dependent on the people and resources available to implement a facility and assemble the right teams [Kiaii 2014].

2. Potential benefits of a hybrid OR for HCR: Allows for a single stage HCR procedure, enables cardiac surgeons, interventional cardiologists, anesthesiologists, nurses and perfusionists to work simultaneously on one table, in one room and uses a team approach, also it includes a percutaneous catheter-based approach, allows for immediate evaluation of the treatment via completion angiogram, and optimizes surgical/interventional results with reduced trauma in a parallel setup [Gąsior 2014].

Operative steps:

I-Direct LIMA harvest in MIDCAB

1. Patient set up: Lines/airway, double lumen ETT with internal jugular central line and positioning is 30 degrees right lateral decubitus with a roll under left shoulder [Kiaii 2014].

2. Thoracotomy/incisions: Perform a 5- to 7-cm anterolateral mini-thoracotomy (male patients: over the 5th or 6th ICS, 1/3 medial to the nipple and female patients: inframammary incision similar location, the medial $2 / 3$ of the window incision is medial to the anterior axillary line) while making the incision, deflate the left lung, divide the intercostal muscles laterally to reduce the risk of rib fracture, then divide them medially to avoid damage to the LIMA and a soft tissue retractor may be placed in the incision to maximize access [Kiaii 2014].

3. Direct LIMA harvest: Place a large Kelly clamp with a sponge in the 6th ICS to assist with harvesting the LIMA, use the sponge to push away tissue for better IMA visualization, insert the MIDCAB retractor system into the ICS incision. In order to prevent crush injury to the LIMA, make sure the superior portion of 
Table 4. Meta-analyses of studies comparing hybrid coronary revascularization with different revascularization options [Lowenstern 2019].

\begin{tabular}{|c|c|c|c|c|c|c|c|c|c|c|c|}
\hline \multicolumn{12}{|l|}{$H C R$ versus $C A B G$} \\
\hline Esteves et al 2020 & $\begin{array}{l}\text { Prospective } \\
\text { randomized }\end{array}$ & $\mathrm{HCR}=40$ & 12.5 & NA & 0 & NA & NA & 2 years & 19.35 .9 & 14.55 .9 & 12.50 .0 \\
\hline Tajstra et al 2018 & $\begin{array}{l}\text { Prospective } \\
\text { randomized }\end{array}$ & $\mathrm{HCR}=94$ & 0 & $\begin{array}{c}19 \\
(P=.23)\end{array}$ & $\begin{array}{c}2.1 \\
(P=0.35)\end{array}$ & 96 & $\begin{array}{l}8.6 \pm 4.1 \\
(P=.86)\end{array}$ & 5 years & $\begin{array}{c}45.4 \\
(P=.39)\end{array}$ & NA & $\begin{array}{c}6.4 \\
(P=.69)\end{array}$ \\
\hline$C A B G=97$ & 0 & 26 & 4.1 & NA & $8.5 \pm 5.2$ & - & 53.4 & - & 9.2 & & \\
\hline $\begin{array}{l}\text { Bachinsky et al } \\
2012\end{array}$ & $\begin{array}{c}\text { Prospective } \\
\text { cohort }\end{array}$ & $\mathrm{HCR}=25$ & $\begin{array}{c}0 \\
(P=.99)\end{array}$ & $\begin{array}{c}12 \\
(P<.001)\end{array}$ & $\begin{array}{c}0 \\
(P=.999)\end{array}$ & NA & $\begin{array}{c}5.1 \pm 2.8 \\
(P=.008)\end{array}$ & 30 days & $\begin{array}{c}0 \\
(P=.999)\end{array}$ & NA & $\begin{array}{c}0 \\
(P=.999)\end{array}$ \\
\hline$O P C A B=216$ & 1 & 28 & 1 & NA & 8.1 & - & NA & 8 & 15 & & \\
\hline Song et al 2016 & $\begin{array}{l}\text { Prospective pro- } \\
\text { pensity matching }\end{array}$ & $\mathrm{HCR}=573$ & NA & $\begin{array}{c}29.2 \% \\
(P=.076)\end{array}$ & $\begin{array}{c}0 \\
(P=.046)\end{array}$ & NA & $\begin{array}{c}7 \\
(P=.627)\end{array}$ & 3 years & $\begin{array}{c}7.4 \\
(P=.612)\end{array}$ & $\begin{array}{c}4.7 \\
(P=.488)\end{array}$ & $\begin{array}{c}2.7 \% \\
(P=1.00)\end{array}$ \\
\hline $\mathrm{OPCAB}=700$ & NA & 39.6 & 3.6 & NA & 7 & - & 8 & 2.3 & 2.8 & & \\
\hline Halkos et al 2011 & $\begin{array}{l}\text { Retrospective } \\
\text { propensity } \\
\text { matching }\end{array}$ & $\mathrm{HCR}=147$ & $\begin{array}{c}0.7 \\
(P=.84)\end{array}$ & $\begin{array}{c}35.4 \% \\
(P<.001)\end{array}$ & $\begin{array}{c}0.7 \\
(P=.8)\end{array}$ & $\begin{array}{c}95.2 \\
(P<.001)\end{array}$ & $\begin{array}{l}6.6 \pm 6.7 \\
(P=.48)\end{array}$ & 5 years & $\begin{array}{c}2 \\
(P=1)\end{array}$ & $\begin{array}{c}12.2 \\
(P<.001)\end{array}$ & $\begin{array}{c}13.2 \\
(P=.61)\end{array}$ \\
\hline $\mathrm{OPCAB}=588$ & 0.9 & $56 \%$ & 0.7 & 99 & $6.1 \pm 4.7$ & - & 2 & 3.7 & 15.7 & & \\
\hline \multicolumn{12}{|c|}{$\mathrm{HCR}$ versus $C A B G$ versus $P C l$} \\
\hline $\mathrm{PCl}=49$ & 0 & 0 & 0 & NA & 13.8 & - & 13.2 & 17 & 3.8 & & \\
\hline$C A B G=51$ & 0 & 20 & 0 & - & 4.5 & - & 12 & 4 & 2 & & \\
\hline Qiu et al 2019 & $\begin{array}{c}\text { Retrospective } \\
\text { propensity } \\
\text { matched cohort }\end{array}$ & $\mathrm{HCR}=47$ & 0 & NA & 4.5 & NA & $\begin{array}{l}15.3 \pm 4.5 \\
(P=.027)\end{array}$ & 4.9 years & $\begin{array}{c}11 \\
(P=.007)\end{array}$ & $\begin{array}{c}4.5 \\
(P=.002)\end{array}$ & $\begin{array}{c}1 \\
(P=.811)\end{array}$ \\
\hline $\mathrm{PCl}=47$ & 0 & NA & 6.8 & NA & NA & - & 35 & 2.2 & 2 & & \\
\hline $\mathrm{OPCAB}=47$ & 2 & NA & 6.8 & NA & $17.6 \pm 5.4$ & - & 13 & 22 & 2 & & \\
\hline Shen et al 2013 & $\begin{array}{c}\text { Retrospective } \\
\text { propensity } \\
\text { matched cohort }\end{array}$ & $\mathrm{HCR}=141$ & NA & 21.3 & $\begin{array}{c}2 \\
(P=.083)\end{array}$ & 98 & $8.19 \pm 2.54$ & 3 years & $\begin{array}{c}9 \\
(P=.003)\end{array}$ & $\begin{array}{c}6 \\
(P<.001)\end{array}$ & $\begin{array}{c}0.7 \\
(P=.034)\end{array}$ \\
\hline $\mathrm{PCl}=141$ & - & NA & 3 & NA & NA & - & 19 & 18 & 3.5 & & \\
\hline$C A B G=141$ & - & 31.9 & 9 & 98 & $\begin{array}{c}8.49 \pm \\
2.54\end{array}$ & - & 32 & 3 & 2.8 & & \\
\hline
\end{tabular}

$\mathrm{HCR}$ versus $\mathrm{PCl}$ 
Table 4. [Cont.]

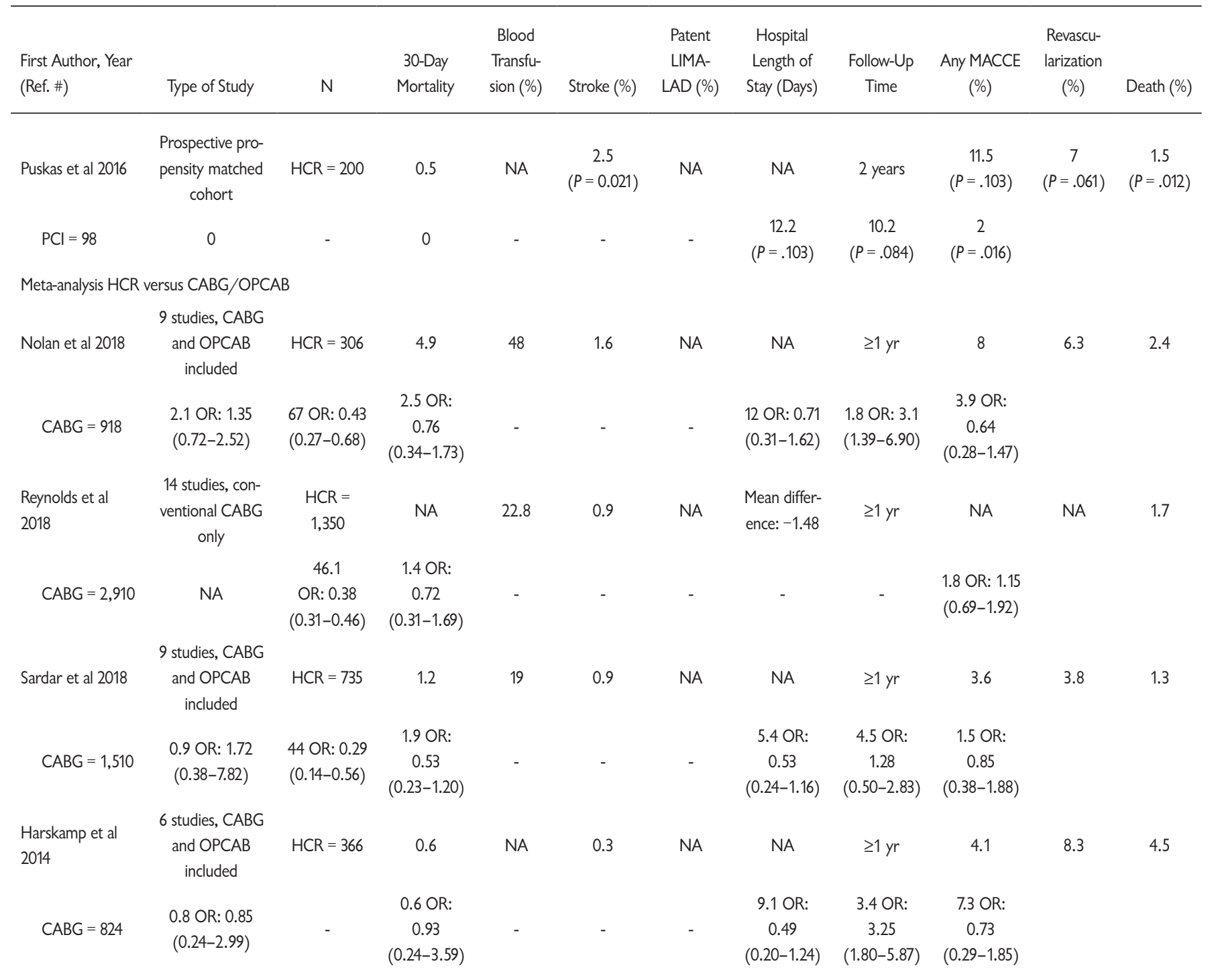

the retractor is placed and maintained in the lateral aspect of the incision. Care should be taken not to fracture a rib, MIDCAB retractor system should be cranked slowly, which allows tissue and bone to acclimate to the change in position in order to minimize the potential for rib fracture and pain. Start the LIMA harvest at the 3rd ICS using direct vision through the window incision, use an extended electrocautery instrument, endoscopic forceps, suction, endoscopic clip applier and small clips for the harvest, complete the harvest up to the subclavian vein and down past the left 5 th ICS, take care to identify and avoid the phrenic nerve. During the LIMA harvest, flexing the table may facilitate access to the superior portion of the LIMA, anchor the pedicle of the LIMA with silk ties to maintain the proper orientation and give intravenous heparin prior to LIMA division [Kiaii 2014].
II. Endoscopic/robotic harvesting of the LIMA and/or RIMA:

1. Patient set up: Positioning is 30 degrees right lateral decubitus with a roll under left chest to allow shoulders to fall.

2. Endoscopic port insertion: The left lung is deflated and in the 5 th ICS $12-\mathrm{mm}$ port inserted, CO2 insufflation for intrathoracic pressure 5 to $10-\mathrm{mmHg}$ (watch blood pressure), 30-degree endoscope inserted. Under the guidance of the endoscope, quantity of two $7-\mathrm{mm}$ ports, inserted in the 3rd and 7th ICS, endoscopically or robotically the LIMA is harvested from 1st rib to the 6th rib, endoscopically the pericardium is opened and the location of the LAD identified and using a spinal needle the location for the thoracotomy is selected to provide the best access to the $\mathrm{LAD}$, prior to ligation of the LAD and patient is given intravenous heparin depending on 1 stage or 2 stage procedure [Kiaii 2014]. 
III- LIMA-LAD anastomosis (applies to direct and robotic harvest techniques): The LIMA-LAD anastomosis is performed under direct vision through the mini-thoracotomy, only soft tissue retraction is generally required, minimizing trauma, open the pericardium down to the diaphragm and toward the right pleura, with the LIMA visible through the incision, place the octopus tissue stabilizer through the 6th ICS if LIMA is directly harvested or 5th ICS if LIMA is endoscopically harvested and stabilize the LAD using suction and once stabilized, the LAD is occluded and the bypass is grafted using standard instruments [Kiaii 2014].

\section{Development of hybrid beart team:}

The performance of HCR depends on the development and maintenance of a cooperative (coronary) heart team. Multiple factors must be common among all centers seeking to provide optimal care for patients with coronary artery disease [Moreno 2020]. These are:

1. A shared recognition of the important roles of team members in the care of coronary patients with multivessel CAD.

2. Collaborative discussion of the relative short- and long-term benefits of guidelines directed medical therapy, PCI, traditional CABG, and HCR to optimize the assignment of patients to each of these alternative therapies.

3. A collective skill set that allows the institutional coronary heart team to offer state-of-the-art care.

4. The decision of the appropriate management should not be based on the competition but on an assurance that all members of our heart team collectively will benefit by fulfilling our ethical obligation to provide the best care to every patient.

\section{OUTCOMES AND VALUES}

The burning question that prevents HCR from taking off remains unanswered: Why should institutes adopt a complex, costly procedure requiring state of-the-art equipment, unique expertise, and close collaboration of interventional cardiologists and cardiac surgeons, when similar survival and morbidity outcomes can be obtained with a well-established, safe procedure available in most hospitals?

Several studies have shown that in well-selected patients, HCR provides better short-term outcomes with regard to decreased ventilation and ICU time, reduced requirement for blood transfusion, and shortened hospital stay. However, there has been no strong evidence regarding improved mortality, and late comparative outcomes are still insufficient. Table 4 shows the results of the most recent studies, comparing HCR with different revascularization modalities.

\section{HCR versus conventional CABG}

The POL-MIDES (Safety and Efficacy Study of Hybrid Revascularization in Multivessel Coronary Artery Disease) trial was a prospective, single-center, randomized, pilot trial of 200 patients comparing HCR with conventional
CABG [Tajstra 2018]. The 5-year respective rates of death $(6.4 \%$ versus $9.2 \%)$, myocardial infarction ( $4.3 \%$ versus $7.2 \%)$, repeat revascularization $(37.2 \%$ versus $45.4 \%)$, and stroke $(2.1 \%$ versus $4.1 \%)$ were numerically in favor of HCR, but comparisons were not statistically significant [Tajstra 2018].

Bachinsky et al reported significant reductions in blood transfusions and hospital length of stay favoring HCR $(P<.01)$ [Bachinsky 2012].

A small, randomized pilot study done by Esteves et al showed no differences in mortality or MACCE at two years, but there was a tendency for increased revascularization and MACCE in the HCR arm compared with in the CABG arm in patients with complex multivessel disease [Esteves 2020].

\section{HCR versus $O P C A B$}

HCR was associated with reduced blood transfusions, chest tube drainage, mechanical ventilation, and ICU stay. MACCE rates were similar in both groups [Halkos 2011; Song 2016]. Finally, Hage et al demonstrated a trend toward reduced mortality over a long period of follow up in patients who underwent single-stage HCR compared with OPCAB [Hage 2019].

\section{HCR versus PCI}

Repossini et al compared HCR to PCI in management of left main stenosis and found that HCR demonstrated a lower incidence of cardiac adverse events, such as AMI and TVR [Repossini 2018].

\section{HCR versus $C A B G$ versus $P C I$}

At three-year follow up, Shen et al found the cumulative MACCE rate in the hybrid group (6.4\%) was significantly lower than that in the PCI group $(22.7 \% ; P<.001)$. However, it was not significantly different than that in the CABG group $(13.5 \% ; P=.14)$ [Shen 2013]. A recent randomized trial, the HREVS trial, compared HCR using a MIDCAB approach to both conventional CABG and PCI in 155 patients [Ganyukov 2020]. They showed that HCR was associated with less bleeding than CABG and had a $10 \%$ conversion rate to sternotomy. The endpoint of residual myocardial ischemia by single-photon emission computed tomography (SPECT) was no different between any of the three groups at one year. Unfortunately, no longer-term follow up is present in either of these trials, where divergence of curves could occur as was seen in the previously mentioned non-hybrid MIDCAB versus PCI trials.

Thus, the question of the true value of HCR remains undetermined. HCR, albeit with higher initial procedural costs but lower in-hospital costs related to lower morbidity, may have the same or better initial value than regular CABG surgery, which is probably offset by future coronary reintervention related to stent restenosis. Therefore, the wide application of HCR is limited by the uncertainty of the long-term effectiveness of DES and the higher cost [Harskamp 2014].

\section{Long-term outcome}

Basman et al found that patients with TVD who underwent HCR had similar 8-year mortality $(5.0 \%)$ as did those with CABG (4.0\%) or multivessel PCI (9.0\%) [Basman 2020] . 
A composite endpoint of death, repeat revascularization, and new myocardial infarction was not significantly different between patient groups (HCR 21.0\% versus CABG 15.0\%, $P=.36$; HCR $21.0 \%$ versus PCI $25.0 \%, P=.60)$. Despite a higher baseline synergy between percutaneous coronary intervention with taxus and cardiac surgery (SYNTAX) score, HCR was able to achieve a lower residual SYNTAX score than multivessel PCI $(P=.001)$.

\section{Current research}

At the University of Arizona Medical Center and by the members of the Khalpey Cardiothoracic Surgery Laboratory, a novel hybrid treatment with transmyocardial revascularization (TMR) and stem cell therapy is currently investigated to heighten this response and provides another avenue by which an ischemic myocardium can be revascularized. The future of TMR therapy and research hinges on its collaboration with stem cell therapies in order to further enhance myocardial repair, regeneration and revascularization [Iwanski 2016].

\section{Future directions}

Despite the promising early- and mid-term results, recovery parameters and patient satisfaction, HCR still remains relatively limited in its use. A number of factors are accountable. First, there have been no large randomized clinical trials that have compared HCR with CABG or multi-vessel PCI to establish an accepted standard of use. In order to demonstrate that HCR is non-inferior or even superior to conventional revascularization strategies in terms of long-term death, myocardial infarction, stroke and additional revascularization, adequately sized randomized controlled clinical trials are warranted. Apart from studies on clinical outcomes, additional studies are needed to study the optimal timing and sequence of procedures as well as the use, timing and dosage of (novel) antiplatelet agents to lower the risks of bleeding and acute stent thrombosis [Harskamp 2016]. Particular interest should be given to women, older adults, individuals with diabetes mellitus or chronic kidney disease, since research on those vulnerable patient populations are currently lacking. Apart from clinical trial data, the construction of national registries with detailed in-hospital data and longitudinal follow up are warranted, as single-center registries currently are too small to address these questions [Harskamp 2016]. Second, there remain numerous logistical challenges, particularly for centers that want to perform one-stage HCR as many institutions do not have the resources for successful implementation of a hybrid revascularization program, which includes the costs associated with planning, hybrid operating room, and training of personnel. Lastly, seamless collaboration of interventional cardiologists and cardiac surgeons, and their respective nursing, technical and planning teams is required to implement a successful HCR program [Harskamp 2016].

\section{CONCLUSIONS}

Despite the intuitive advantages of the HCR approach in combining the best that both CABG and PCI have to offer, the safety, efficacy and cost-effectiveness of this approach must be proven in appropriately powered randomized trials, especially given the upfront costs of performing two procedures (in most HCR strategies) as opposed to a single multivessel PCI or CABG.

\section{ACKNOWLEDGEMENT}

Funding: This project was funded by the Deanship of Scientific Research (DSR), King Abdulaziz University, under grant No. (DF-823-140-1441).

\section{REFERENCES}

Angelini GD, Wilde P, Salerno TA, Bosco G, Calafiore AM. 1996. Integrated left small thoracotomy and angioplasty for multivessel coronary artery revascularization. Lancet. 347:757-758.

Bachinsky WB, Abdelsalam M, Boga G, Kiljanek L, Mumtaz M, McCarty C. 2012. Comparative study of same sitting hybrid coronary artery revascularization versus off-pump coronary artery bypass in multivessel coronary artery disease. J Interv Cardiol. 25:460-8.

Basman C, Hemli JM, Kim MC, et al. 2020. Long-term survival in triplevessel disease: Hybrid coronary revascularization compared to contemporary revascularization methods. J Card Surg. 35: 2710- 2718.

Bonatti J, Lehr E, Vesely MR, Friedrich G, Bonaros N, Zimrin D. 2010. Hybrid coronary revascularization: which patients? When? How? Curr Opin Cardiol. 25:568-574.

Chen JP, Srivastava S. 2010. A vanishing lesion. J Am Coll Cardiol Intv. 3:360-1.

Choi HJ, Kang J, Song H, Kim DY, Choi KB. 2017. Comparison of Coronary Artery Bypass Graft-First and Percutaneous Coronary Intervention-First Approaches for 2-Stage Hybrid Coronary Revascularization. Korean J Thorac Cardiovasc Surg. 50(4):247-254.

de Cannière D, Jansens JL, Goldschmidt-Clermont P, Barvais L, Decroly P, Stoupel E. 2001. Combination of minimally invasive coronary bypass and percutaneous transluminal coronary angioplasty in the treatment of doublevessel coronary disease: Two-year follow-up of a new hybrid procedure compared with "on-pump" double bypass grafting. Am Heart J. 142: $563-570$.

Esteves V, Oliveira MAP, Feitosa FS, et al. 2020. Late clinical outcomes of myocardial hybrid revascularization versus coronary artery bypass grafting for complex triple- vessel disease: long-term follow-up of the randomized MERGING clinical trial. Catheter Cardiovasc Interv. Jan 10 [E-pub ahead of print].

Ganyukov V, Kochergin N, Shilov A, et. al. 2020. Randomized clinical trial of surgical vs. percutaneous vs. hybrid revascularization in multivessel coronary artery disease: residual myocardial ischemia and clinical outcomes at one year-Hybrid Coronary Revascularization Versus Stenting or Surgery (HREVS). J Interv Cardiol. pp. 5458064.

Gąsior M, Zembala MO, Tajstra M. 2014. Hybrid revascularization for multivessel coronary artery disease. JACC Cardiovasc Interv. Nov;7(11):1277-83.

Giambruno V, Hafiz A, Fox SA, Jeanmart H, Cook RC, Khaliel FH, Teefy P, Sridhar K, Lavi S, Bagur R, Randhawa VK, Iglesias I, Jones PM, Harle CC, Bainbridge D, Chu MW, Kiaii BB. 2017. Is the Future of Coronary Arterial Revascularization a Hybrid Approach? The Canadian Experience 
Across Three Centers. Innovations (Phila). Mar/Apr;12(2):82-86.).

Hage A, Giambruno V, Jones P, et al. 2019. Hybrid coronary revascularization versus off-pump coronary artery bypass grafting: comparative effectiveness analysis with long-term follow-up. J Am Heart Assoc. 8: e014204.

Halkos ME, Ford L, Peterson D, Bluestein SM, Liberman HA, Kilgo P, Puskas JD, Guyton RA, Chowdhury R. 2014. The impact of hybrid coronary revascularization on hospital costs and reimbursements. Ann Thorac Surg. 97:1610-1615.

Halkos ME, Vassiliades TA, Douglas JS, et al. 2011. Hybrid coronary revascularization versus off-pump coronary artery bypass grafting for the treatment of multivessel coronary artery disease. Ann Thorac Surg. 92:1695-702.

Harskamp RE. 2015. Current state and future direction of hybrid coronary revascularization. Curr Opin Cardiol. 30: 643-649.

Harskamp RE. 2016. Hybrid coronary revascularization: at the crossroads of surgical and percutaneous interventions, university of Amsterdam, Thesis. a-page:20, b-page:53.

Harskamp RE, Brennan JM, Xian Y, Halkos ME, Puskas JD, Thourani VH, et al. 2014. Practice patterns and clinical outcomes after hybrid coronary revascularization in the United States: an analysis from the Society of Thoracic Surgeons Adult Cardiac Database. Circulation. 130:872-879.

Harskamp RE, Zheng Z, Alexander JH, Williams JB, Xian Y, Halkos ME, et al. 2013. Status Quo of Hybrid Coronary Revascularization for Multi-Vessel Coronary Artery Disease. Ann Thorac Surg. 96:2268-77.

Hillis LD, Smith PK, Anderson JL, et al. 2011. 2011 ACCF/AHA guideline for coronary artery bypass graft surgery: a report of the American College of Cardiology Foundation/American Heart Association Task Force on Practice Guidelines. J Am Coll Cardiol. 58: e123-e210.

Igor G, Marzia L. 2014. Hybrid Coronary Revascularization: the Future of Coronary Artery Bypass Surgery or an Unfulfilled Promise? Circulation. 130:869-871.

Iwanski J, Raymond K, Douglas F, Alice S, Raymond B, Goldstein S, et al. 2016. Remodeling an infarcted heart: novel hybrid treatment with transmyocardial revascularization and stem cell therapy. Springerplus. 5(1): 738 .

Kiaii B, Teefy P, Sridhar K, Chu M. 2014. Hybrid Coronary Revascularization, London heart sciences centre, technique guide.

Lioyd CT, Calafiore AM, Wilde P, et al. 1999. Integrated left anterior small thoracotomy and angioplasty for coronary artery revascularization. Ann Thorac Surg. 68:908-911.

Lowenstern A, Wu J, Bradley SM, Fanaroff AC, Tcheng JE, Wang TY. 2019. Current landscape of hybrid revascularization: a report from the NCDR CathPCI Registry. Am Heart J. 215:167-77.

Moreno PR, Stone GW, Gonzalez-Lengua CA, Puskas JD. 2020. The Hybrid Coronary Approach for Optimal Revascularization: JACC Review Topic of the Week. J Am Coll Cardiol. Jul 21;76(3):321-333.

Murphy GJ, Bryan AJ, Angelini GD. 2004. Hybrid coronary revascularization in the era of drug-eluting stents. Ann Thorac Surg. 78:1861 1867.

Nakayoshi T, Ueno T, Sasaki KI, et al. 2016. Differential angioscopic findings of neointimal coverage among first-, second-, and next generation drug-eluting stents. Int J Cardiol. 223: 450-451.

Neumann FJ, Sousa-Uva M, Ahlsson A, et al. 2019. ESC Scientific Document Group, 2018 ESC/EACTS Guidelines on myocardial revascularization, European Heart Journal, Volume 40, Issue 2, 07 January, Pages
$87-165$.

Puskas JD, Halkos ME, Derose JJ, et al. 2016. Hybrid coronary revascularization for the treatment of multivessel coronary artery disease: a multicenter observational study. J Am Coll Cardiol. 68: 356-65.

Rastan AJ, Walther T, Falk V, et al. 2009. Does reasonable incomplete surgical revascularization affect early or long-term survival in patients with multivessel coronary artery disease receiving left internal mammary artery bypass to left anterior descending artery? Circulation.120: 70-77.

Repossini A, Di Bacco L, Rosati F, et al. 2018. Hybrid coronary revascularization versus percutaneous strategies in left main stenosis: a propensity match study. J Cardiovasc Med (Hagerstown). 19:253-60.

Rodriguez M and Ruel M. 2016. Minimally Invasive Multivessel Coronary Surgery and Hybrid Coronary Revascularization: Can We Routinely Achieve Less Invasive Coronary Surgery?. Methodist Debakey Cardiovasc J. Jan-Mar; 12(1): 14-19.

Saha T, Naqvi SY, Goldberg S. 2018. Hybrid Revascularization: A Review. Cardiology. 140(1):35-44).

Shen L, Hu S, Wang H, et al. 2013. One-stop hybrid coronary revascularization versus coronary artery bypass grafting and percutaneous coronary intervention for the treatment of multivessel coronary artery disease: 3-year follow-up results from a single institution. J Am Coll Cardiol. 61: 2525-33.

Sianos G, Morel MA, Kappetein AP, et al. 2005. The SYNTAX score: an angiographic tool grading the complexity of coronary artery disease. EuroIntervention. 1:219-227.

Song Z, Shen L, Zheng Z, et al. 2016. One-stop hybrid coronary revascularization versus off-pump coronary artery bypass in patients with diabetes mellitus. J Thorac Cardiovasc Surg. 151: 1695-701.

Srivastava S, Gadasalli S, Agusala M, et al. 2010. Beating heart totally endoscopic coronary artery bypass. Ann Thorac Surg. 89:1873-9.

Taggart DP, Altman DG, Gray AM, Lees B, Gerry S, Benedetto U, Flather M. 2016. Randomized trial of bilateral versus single internalthoracic-artery grafts. N Engl J Med. 375: 2540- 2549.

Tajstra M, Hrapkowicz T, Hawranek M, et al. 2018. for the POLMIDES Study Investigators. Hybrid coronary revascularization in selected patients with multivessel disease: 5 -year clinical outcomes of the prospective randomized pilot study. J Am Coll Cardiol Intv. 11:847-52.

Teo KK, Cohen E, Buller C, et al. 2014. Canadian Cardiovascular Society/Canadian Association of Interventional Cardiology/Canadian Society of Cardiac Surgery position statement on revascularization--multivessel coronary artery disease. Can J Cardiol. 30: 1482-1491.

Vasileios FP, Antonio C, Alberto M, Francesco. 2015. Hybrid Coronary Revascularization Promising, But Yet to Take Off. Journal of American College of Cardiology. $65: 120-126$.

Vassiliades TA, Kilgo PD, Douglas JS, et al. 2009. Clinical outcomes after hybrid coronary revascularization versus off-pump coronary artery bypass: a prospective evaluation. Innovations (Phila). 4:299-306.

Windecker S, Kolh P, Alfonso F, et al. 2014. 2014 ESC/EACTS guidelines on myocardial revascularization: The Task Force on Myocardial Revascularization of the European Society of Cardiology (ESC) and the European Association for Cardio-Thoracic Surgery (EACTS). EuroIntervention. Sep 3.

Yamaji K, Raber L, Zanchin T, et al. 2016. Ten-year clinical outcomes of first-generation drug-eluting stents: the Sirolimus-Eluting vs PaclitaxelEluting Stents for Coronary Revas`cularization (SIRTAX) VERY LATE trial. Eur Heart J. 37: 3386-3395. 